\title{
Efeito do gérmen integral de milho sobre o desempenho e rendimento de carcaça de frangos de corte
}

[Effects of corn germ meal on broiler performance and carcass yield]

\author{
A.B. Brito ${ }^{1}$, J.H. Stringhini ${ }^{2,3 *}$, C.P. Cruz ${ }^{4,5}$, S.A.G. Xavier ${ }^{1,3}$, N.S.M. Leandro ${ }^{2}$, M.B. Café ${ }^{2}$ \\ ${ }^{1}$ Pós-graduando em Ciência Animal - EVUFG \\ ${ }^{2}$ Departamento de Produção Animal - Escola de Veterinária - Universidade Federal de Goiás \\ Campus II Samambaia - Caixa Postal 131 \\ 74001-970 - Goiânia, GO \\ ${ }^{3}$ Bolsista do CNPq
}

\begin{abstract}
RESUMO
Realizaram-se dois experimentos com 1008 pintos machos Ag-Ross $508 \mathrm{em}$ cada um deles. No primeiro, avaliou-se o desempenho de frangos de corte alimentados com diferentes níveis de gérmen integral de milho (GIM) na dieta de um a sete dias de idade (fase pré-inicial). No segundo, avaliou-se o desempenho e o rendimento de carcaça no período de oito a 47 dias. As aves foram alojadas em 16 unidades, divididas em quatro tratamentos, de acordo com os níveis de GIM, em substituição ao milho na dieta $(0 \%, 33 \%$, $67 \%$ e $100 \%$ ), e quatro repetições de 63 aves cada. Utilizou-se o delineamento inteiramente ao acaso, e os dados foram analisados por regressão polinomial. O GIM não foi um bom alimento para a fase pré-inicial. A inclusão recomendada do GIM foi de $21,9 \%$ e $22,5 \%$ nos períodos de oito a 21 dias e de 22 a 38 dias, respectivamente. Não houve restrição do uso do GIM na fase final.
\end{abstract}

Palavras-chave: frango de corte, desempenho, gérmen integral de milho, rendimento de carcaça

\begin{abstract}
Two experiments were carried out with 1008 male Ag-Ross 508 broilers each. Experiment 1 was carried out from October $26^{\text {th }}$ to November $1^{\text {st }}$, 2001 to evaluate the performance of broilers fed on increasing levels of corn germ meal (CGM) in the diets from 1 to 7 days of age. Experiment 2 was carried from January $24^{\text {th }}$ to March $12^{\text {th }}$, 2002 to evaluate the performance and carcass yield from 8 to 47 days. The birds were allotted to a completely randomized design with four treatments (levels of CGM replacing corn in ration - $0 \%, 33 \%, 67 \%$ and $100 \%$ ) and four replicates of 63 birds. The CGM was not a good ingredient for pre-starter phase. The recommended inclusion levels of CGM were $21.9 \%$ and $22.5 \%$ from 8 to 21 days and from 22 to 38 days, respectively. No restriction concerning the use of CGM for diets of broilers from 39 to 47 days of age is made.
\end{abstract}

Keywords: broiler, carcass yield, corn germ meal, performance

\section{INTRODUÇ̃̃O}

Os produtos resultantes da indústria de beneficiamento de grãos apresentam alto potencial de utilização, mas necessitam de permanente avaliação, para que sejam usados corretamente na dieta das aves, principalmente quanto à qualidade nutricional e ao nível de inclusão (Teichmann et al., 1998; Garcia et al., 2000).

Recebido para publicação em 10 de novembro de 2003

Recebido para publicação, após modificações, em 15 de junho de 2004

*Autor para correspondência (corresponding author)

E-mail: jhstring@uol.com.br 
O gérmen integral de milho (GIM) é definido como o resultado da trituração do gérmen, do tegumento e das partículas amiláceas, obtidos por extração mecânica, e com alto teor de extrato etéreo (Compêndio..., 1985). O gérmen compõe cerca de $13 \%$ do peso total do milho grão e pode ser utilizado como concentrado energético. Pode, ainda, ser submetido ao processo de extração de gordura por solvente, gerando o gérmen de milho desengordurado, rico em proteína $(10,8 \%$ de proteína bruta) e com $2.393 \mathrm{kcal} / \mathrm{kg}$ de energia metabolizável (Butolo et al., 1998).

É possível fazer um paralelo dos resultados de desempenho de frangos de corte que receberam GIM com aqueles obtidos em experimentos que envolveram milho com maior conteúdo energético ou milho alto óleo, pois a elevação do conteúdo de óleo é obtida pela seleção genética no grão para o aumento da fração de gérmen. Em trabalhos como esses, o peso corporal e a eficiência alimentar melhoraram para as aves alimentadas com milho contendo alto teor energético, quando comparados àquelas que receberam dietas com milho convencional e óleo de soja, o que pode ser atribuído ao melhor aproveitamento energético da ave em dietas que contêm milho alto óleo, em contraposição à dieta padrão (Adams et al., 1994; Vieira et al., 1997; Parsons et al., 1998; Benitez et al., 1999).

Outro fator importante da utilização de alimentos com altos níveis de óleo na dieta é a sua facilidade de peletização, principalmente quanto à agregação da massa que resulta desse processo (Penz Jr., 2002).

O milho possui as proteínas zeína e gluteína em sua estrutura. A zeína, contida no endosperma do grão, tem reduzido valor biológico, em decorrência do desequilíbrio provocado pelo alto teor de leucina e pela deficiência de lisina e de triptofano. A gluteína, contida no gérmen do milho, possui valor biológico elevado, principalmente quanto ao balanço de aminoácidos essenciais (Regina e Solferini, 2002).

Assim, este trabalho teve o objetivo de determinar os níveis de inclusão do GIM em substituição ao milho grão na dieta de frangos de corte, tendo como base os resultados de desempenho e rendimento de carcaça.

\section{MATERIAL E MÉTODOS}

Realizaram-se dois experimentos no aviário experimental da Fazenda São Roque, de propriedade do Abatedouro São Salvador (Itaberaí - GO): um no período de 26 de outubro a $1^{\circ}$ de novembro de 2001 (experimento 1); e outro no período de 24 de janeiro a 12 de março de 2002 (experimento 2). De acordo com o recomendado por Brito (2002), adotou-se para o GIM, o seguinte valor nutricional: energia metabolizável aparente corrigida (EMAn) $3.340 \mathrm{kcal} / \mathrm{kg}$, proteína bruta (PB) $10,9 \%$, cálcio (Ca) 0,02\%, fósforo disponível (Pdisp) 0,07\%, lisina total (Lys) $0,41 \%$, metionina total (Met) $0,18 \%$, metionina + cistina total (Met + Cis) $0,41 \%$, triptofano total (Trp) $0,09 \%$, treonina total (Tre) $0,38 \%$, arginina total (Arg) 0,62\%, extrato etéreo (EE) $9,3 \%$, fibra bruta (FB) $5,4 \%$.

No experimento 1, avaliou-se o desempenho de frangos de corte alimentados com diferentes níveis de GIM, na dieta, na fase pré-inicial (um a sete dias), em que se utilizaram 1008 pintos de um dia de idade da linhagem Ag Ross 508, todos machos, alojados em grupos de 63 aves, distribuídas num total de 16 unidades experimentais. As aves foram alojadas em um galpão de alvenaria, dividido, portanto, em 16 boxes de $2,10 \times 2,50 \mathrm{~m}$ cada $\left(5,30 \mathrm{~m}^{2}\right)$.

Procedeu-se à pesagem das aves e das dietas no primeiro e sétimo dias de idade, cujos dados constituíram a base para o cálculo do ganho de peso, do consumo de ração e do índice de conversão alimentar. Avaliou-se o número de aves mortas, e os valores encontrados foram tabulados para a determinação do índice de mortalidade, que, para a análise estatística, foi transformado em arco seno.

Para a formulação das dietas experimentais, levaram-se em consideração os níveis de substituição do milho grão da dieta por GIM, sendo: $0 \%$ (dieta-controle), $33 \%, 67 \%$ e $100 \%$, atendendo às recomendações nutricionais e à composição dos alimentos (Rostagno et al., 2000), sendo todas isonutritivas e isoenergéticas (Tab. 1), exceto para FB e EE.

No experimento 2, avaliou-se o desempenho de frangos de corte alimentados com diferentes níveis de GIM na dieta de oito a 47 dias de idade, também com 1008 pintos de um dia de idade, da 
linhagem Ag Ross 508, todos machos, alojados em grupos de 63 aves, distribuídas em 16 unidades experimentais.

Tabela 1. Composição percentual das dietas experimentais pré-iniciais (um a sete dias de idade) para frangos de corte alimentados com diferentes níveis de substituição do milho por gérmen integral de milho (GIM) na dieta (experimento 1)

\begin{tabular}{lcccc}
\hline \multirow{2}{*}{ Ingrediente } & \multicolumn{4}{c}{ Nível de substituição } \\
& 0 & 33 & 67 & 100 \\
\hline Milho & 57,19 & 41,00 & 24,32 & 8,14 \\
Farelo de soja (45\%) & 28,08 & 27,56 & 27,06 & 26,58 \\
Gérmen integral de milho & 0,00 & 18,87 & 38,32 & 57,19 \\
Soja integral tostada & 10,58 & 8,31 & 5,96 & 3,68 \\
Fosfato bicálcico & 1,89 & 1,89 & 1,89 & 1,88 \\
Calcário & 1,06 & 1,07 & 1,08 & 1,09 \\
Premix min-vit ${ }^{1}$ & 0,41 & 0,41 & 0,41 & 0,41 \\
Sal branco & 0,46 & 0,47 & 0,48 & 0,49 \\
DL-Metionina 99 & 0,19 & 0,21 & 0,23 & 0,25 \\
L-Lisina HCl 78,5\% & 0,14 & 0,19 & 0,20 & 0,21 \\
L-Treonina & 0,00 & 0,01 & 0,03 & 0,03 \\
L-Triptofano & 0,00 & 0,01 & 0,02 & 0,05 \\
Composição calculada ${ }^{2}$ & & & & \\
EMAn, kcal/kg & 2.950 & 2.950 & 2.950 & 2.950 \\
Proteína bruta, \% & 21,90 & 21,90 & 21,90 & 21,90 \\
Cálcio, \% & 0,99 & 0,99 & 0,99 & 0,99 \\
Pdisponível, \% & 0,47 & 0,47 & 0,47 & 0,47 \\
Lisina, \% & 1,30 & 1,30 & 1,30 & 1,30 \\
Metionina + cistina, \% & 0,88 & 0,88 & 0,88 & 0,88 \\
Metionina, \% & 0,53 & 0,54 & 0,55 & 0,57 \\
Treonina, \% & 0,84 & 0,84 & 0,84 & 0,84 \\
Triptofano, \% & 0,28 & 0,28 & 0,28 & 0,28 \\
Extrato etéreo, \% & 4,06 & 5,11 & 6,20 & 7,25 \\
Fibra bruta, \% & 3,48 & 3,99 & 4,53 & 5,04 \\
\hline 1 Premix Mineral e Vitamínico C 115-Nutron “Frango inicial \\
completo sem metionina”. & & & & \\
2 Valores calculados segundo Rostagno et al. (2000). & \\
& & & &
\end{tabular}

Durante a fase pré-inicial (um a sete dias) as aves receberam uma dieta à base de milho e farelo de soja segundo Rostagno et al. (2000). Para as fases inicial (oito a 21 dias), de crescimento (22 a 38 dias) e final (39 a 47 dias), as dietas foram formuladas levando-se em consideração os níveis de substituição do milho pelo GIM, semelhante ao experimento anterior. Houve a necessidade de adicionar milho na dieta com $100 \%$ de substituição, para o correto balanceamento dos nutrientes, o que não afetou o nível total de GIM (Tab. 2).

A pesagem das aves e das dietas foi realizada no oitavo, $21^{\circ}, 38^{\circ}$ e $47^{\circ}$ dias de idade, cujos dados constituíram a base para o cálculo do ganho de peso, do consumo de ração e do índice de conversão alimentar. Avaliou-se também o índice de mortalidade.

Ao final dos 47 dias, quatro aves por repetição, representando a média do boxe, foram processadas no Abatedouro São Salvador, em Itaberaí (GO), para a avaliação do rendimento de carcaça e de cortes.

Realizou-se a pesagem das aves vivas na plataforma do abatedouro, das carcaças evisceradas (não resfriadas em chiller), dos cortes (peito, dorso, asa, pernas, pés, pescoço + cabeça) e da gordura abdominal, esta última considerada como a quantidade aderida na moela e no pró-ventrículo. Os valores obtidos foram tabulados e relacionados ao peso vivo e ao peso de carcaça das aves, sendo apresentados em percentagem.

O delineamento experimental de ambos os experimentos foi inteiramente ao acaso, com quatro tratamentos, correspondendo aos níveis de substituição do milho pelo GIM na dieta e quatro repetições, com 63 aves cada, totalizando 16 unidades experimentais. Todas as análises foram feitas utilizando o SAEG (Sistema..., 1997), decompondo-se os graus de liberdade dos efeitos significativos dos níveis de substituição do milho por gérmen integral de milho em polinômios. 
Brito et al.

Tabela 2. Composição percentual das dietas experimentais de frangos de corte com um a 47 dias de idade alimentados com diferentes níveis de substituição do milho por germe integral de milho (GIM) na dieta (experimento 2)

\begin{tabular}{|c|c|c|c|c|c|c|c|c|c|c|c|c|c|}
\hline \multirow{3}{*}{ Ingrediente } & \multirow{3}{*}{$\begin{array}{c}\text { Fase } \\
\text { pré-inicial }\end{array}$} & \multicolumn{12}{|c|}{ Nível de substituição do milho pelo GIM (\%) } \\
\hline & & \multicolumn{4}{|c|}{ Fase inicial ( 8 a 21 dias) } & \multicolumn{4}{|c|}{ Fase de crescimento (22 a 38 dias) } & \multicolumn{4}{|c|}{ Fase final (39 a 47 dias) } \\
\hline & & 0 & 33 & 67 & 100 & 0 & 33 & 67 & 100 & 0 & 33 & 67 & 100 \\
\hline Milho & 57,19 & 59,24 & 42,41 & 25,03 & 8,14 & 62,10 & 43,06 & 23,45 & 4,47 & 65,08 & 44,96 & 24,56 & 4,74 \\
\hline Farelo de soja (45\%) & 28,08 & 22,18 & 22,04 & 21,88 & 21,78 & 15,87 & 17,57 & 19,34 & 21,02 & 12,12 & 13,79 & 15,12 & 16,45 \\
\hline GIM & 0,00 & 0,00 & 19,60 & 39,80 & 59,40 & 0,00 & 20,50 & 41,62 & 62,12 & 0,00 & 21,44 & 43,50 & 64,97 \\
\hline Soja integral tostada & 10,58 & 14,42 & 11,78 & 9,12 & 6,53 & 18,18 & 15,00 & 11,71 & 8,49 & 19,44 & 16,53 & 13,54 & 10,59 \\
\hline Fosfato bicálcico & 1,89 & 1,79 & 1,71 & 1,63 & 1,54 & 1,63 & 1,61 & 1,59 & 1,58 & 1,35 & 1,26 & 1,18 & 1,09 \\
\hline Calcário & 1,06 & 0,99 & 1,05 & 1,12 & 1,18 & 0,96 & 0,97 & 0,98 & 0,99 & 1,08 & 1,08 & 1,14 & 1,19 \\
\hline Premix min-vit ${ }^{1}$ & 0,41 & 0,41 & 0,41 & 0,41 & 0,41 & 0,42 & 0,42 & 0,42 & 0,42 & 0,23 & 0,23 & 0,23 & 0,23 \\
\hline Sal branco & 0,46 & 0,47 & 0,47 & 0,47 & 0,46 & 0,43 & 0,42 & 0,42 & 0,41 & 0,35 & 0,36 & 0,37 & 0,39 \\
\hline DL-Metionina 99 & 0,19 & 0,22 & 0,25 & 0,27 & 0,29 & 0,20 & 0,20 & 0,20 & 0,21 & 0,18 & 0,17 & 0,17 & 0,16 \\
\hline L-Lisina $\mathrm{HCl}$ 78,5\% & 0,14 & 0,28 & 0,25 & 0,21 & 0,19 & 0,21 & 0,20 & 0,18 & 0,17 & 0,17 & 0,15 & 0,14 & 0,10 \\
\hline L-Treonina & 0,00 & 0,00 & 0,02 & 0,04 & 0,06 & 0,00 & 0,03 & 0,06 & 0,07 & 0,00 & 0,02 & 0,03 & 0,06 \\
\hline L-Triptofano & 0,00 & 0,00 & 0,01 & 0,02 & 0,02 & 0,00 & 0,02 & 0,03 & 0,05 & 0,00 & 0,01 & 0,02 & 0,03 \\
\hline Nutrientes & & & & & & Comp & cão calc & & & & & & \\
\hline EMAn, kcal/kg & 2.950 & 3.000 & 3.000 & 3.000 & 3.000 & 3.075 & 3.075 & 3.075 & 3.075 & 3.150 & 3.150 & 3.150 & 3.150 \\
\hline Proteína bruta, $\%$ & 21,90 & 20,86 & 20,86 & 20,86 & 20,86 & 19,69 & 19,69 & 19,69 & 19,69 & 18,53 & 18,53 & 18,53 & 18,53 \\
\hline Cálcio, \% & 0,99 & 0,95 & 0,95 & 0,95 & 0,95 & 0,88 & 0,88 & 0,88 & 0,88 & 0,85 & 0,85 & 0,85 & 0,85 \\
\hline Pdisp, \% & 0,47 & 0,45 & 0,45 & 0,45 & 0,45 & 0,41 & 0,41 & 0,41 & 0,41 & 0,37 & 0,37 & 0,37 & 0,37 \\
\hline Lisina, $\%$ & 1,30 & 1,24 & 1,24 & 1,24 & 1,24 & 1,16 & 1,16 & 1,16 & 1,16 & 1,09 & 1,09 & 1,09 & 1,09 \\
\hline Metionina + cistina, \% & 0,88 & 0,88 & 0,89 & 0,88 & 0,88 & 0,83 & 0,83 & 0,83 & 0,83 & 0,78 & 0,78 & 0,78 & 0,78 \\
\hline Metionina, $\%$ & 0,53 & 0,55 & 0,56 & 0,58 & 0,59 & 0,51 & 0,51 & 0,51 & 0,52 & 0,46 & 0,47 & 0,46 & 0,47 \\
\hline Treonina, \% & 0,84 & 0,81 & 0,81 & 0,81 & 0,81 & 0,77 & 0,77 & 0,77 & 0,77 & 0,73 & 0,73 & 0,73 & 0,73 \\
\hline Triptofano, \% & 0,28 & 0,25 & 0,26 & 0,26 & 0,26 & 0,23 & 0,23 & 0,23 & 0,23 & 0,26 & 0,26 & 0,26 & 0,26 \\
\hline Extrato etéreo, \% & 4,06 & 4,96 & 5,98 & 7,05 & 8,08 & 3,04 & 4,99 & 6,60 & 8,00 & 2,65 & 4,33 & 6,05 & 7,73 \\
\hline Fibra bruta, \% & 3,48 & 3,38 & 3,89 & 4,42 & 4,93 & 3,30 & 3,85 & 4,42 & 4,98 & 3,11 & 3,76 & 4,41 & 5,04 \\
\hline
\end{tabular}

Fibra brutc

$3,48 \quad 3,38 \quad 3,89 \quad$

${ }_{2}^{2}$ Valores calculados segundo Rostagno et al. (2000). 


\section{RESULTADOS E DISCUSSÃO}

A média do peso das aves ao alojamento no primeiro experimento foi de $44,0 \pm 0,5 \mathrm{~g}$. Na fase pré-inicial, observou-se efeito linear negativo (Tab. 3) para o ganho de peso $(\mathrm{Y}=105,733$ 0,147883X); para o consumo de ração, índice de conversão alimentar e índice de mortalidade, não se verificaram efeitos significativos com a inclusão de GIM na ração.

Tabela 3. Ganho de peso (GP), consumo de ração $(\mathrm{CR})$, índice de conversão alimentar (CA) e índice de mortalidade (Mort) de frangos de corte alimentados com dietas contendo níveis crescentes de substituição do milho por gérmen integral de milho (GIM) na fase pré-inicial (um a sete dias de idade)

\begin{tabular}{lcccc}
\hline $\begin{array}{l}\text { Nível de } \\
\text { substituição (\%) }\end{array}$ & GP $(\mathrm{g})$ & $\mathrm{CR}(\mathrm{g})$ & $\mathrm{CA}(\mathrm{g} / \mathrm{g})$ & Mort (\%) \\
\hline 0 & $103,5 \mathrm{a}$ & 126,0 & 1,218 & 0,8 \\
33 & $102,3 \mathrm{ab}$ & 124,2 & 1,215 & 2,4 \\
67 & $99,6 \mathrm{~b}$ & 125,7 & 1,257 & 3,6 \\
100 & $88,0 \mathrm{~b}$ & 114,6 & 1,348 & 2,8 \\
Efeito & $\mathrm{L}$ & $\mathrm{ns}$ & $\mathrm{ns}$ & $\mathrm{ns}$ \\
$\mathrm{R}^{2}$ & 0,80 & - & - & - \\
$\mathrm{CV}(\%)$ & 5,47 & 4,66 & 4,12 & 17,77 \\
Probabilidade & 0,14 & 11,50 & 6,26 & 14,01 \\
(\%) & &
\end{tabular}

$\mathrm{L}=$ efeito linear do nível de GIM; ns = não significativo pelo teste $\mathrm{F}(\mathrm{P}>0,05) ; \mathrm{R}^{2}=$ coeficiente de determinação; $\mathrm{CV}=$ coeficiente de variação.

Valores seguidos por letras distintas na mesma coluna diferem entre si pelo teste Tukey $(\mathrm{P}<0,05)$.

Embora os níveis da maioria dos nutrientes e de energia metabolizável tenham se mantido constantes nas quatro dietas, o aumento nos valores de FB e de EE, apresentados na Tab. 1, pode ter sido determinante para a obtenção dos valores para o ganho de peso na fase pré-inicial. Vale destacar que a diminuição no desempenho é verificada para todas as fases de criação das aves no que se refere ao aumento dos níveis de fibra e de gordura na dieta (Scott e Boldaji, 1997).

O GIM é rico em gordura, e os lipídios não são eficientemente digeridos e absorvidos na primeira semana de vida da ave, dadas as limitações na maturidade do trato digestivo (Penz Jr. e Vieira, 1998), o que requer, segundo Furlan e Macari (2002), a presença de sais biliares, da lipase pancreática e da colipase, cujas concentrações, dessas últimas, nos intestinos dos pintos recém-eclodidos, são aparentemente baixas e aumentam quando os animais atingem cinco dias de idade. Serafin e Nesheim (1970) sugeriram que pintos recém-eclodidos não conseguem aumentar a secreção de sais biliares, mesmo quando há demanda, ou seja, com aumento de gordura na dieta. Portanto, a quantidade de gordura e de fibra da dieta compromete bastante a digestibilidade e, por conseqüência, o desempenho na fase pré-inicial, relacionando-se principalmente à imaturidade do sistema digestivo nessa fase.

No experimento 2, a média do peso das aves no oitavo dia foi de $144,4 \pm 7,6 \mathrm{~g}$. Para o período de oito a 21 dias (Tab. 4), foi observado efeito quadrático para o ganho de peso $(\mathrm{Y}=632,15+$ $\left.2,23195 \mathrm{X}-0,0302 \mathrm{X}^{2}\right)$ e para o índice de conversão alimentar $(\mathrm{Y}=1,584-0,002912 \mathrm{X}+$ $\left.0,0000465 \mathrm{X}^{2}\right)$, o que não ocorreu para $\mathrm{o}$ consumo de ração e índice de mortalidade.

Tabela 4. Ganho de peso (GP), consumo de ração (CR), índice de conversão alimentar (CA) e índice de mortalidade (Mort) de frangos de corte alimentados com dietas contendo níveis crescentes de substituição do milho por gérmen integral de milho (GIM) na fase inicial (oito a 21 dias de idade)

\begin{tabular}{lcccc}
\hline $\begin{array}{l}\text { Nível de } \\
\text { substituição (\%) }\end{array}$ & GP $(\mathrm{g})$ & CR $(\mathrm{g})$ & $\mathrm{CA}(\mathrm{g} / \mathrm{g})$ & Mort (\%) \\
\hline 0 & $630,8 \mathrm{~b}$ & 1003,8 & $1,591 \mathrm{bc}$ & 0,4 \\
33 & $676,8 \mathrm{a}$ & 1025,3 & $1,515 \mathrm{c}$ & 0,0 \\
67 & $642,2 \mathrm{~b}$ & 1040,7 & $1,620 \mathrm{~b}$ & 0,4 \\
100 & $554,5 \mathrm{c}$ & 969,4 & $1,749 \mathrm{a}$ & 1,3 \\
Efeito & $\mathrm{Q}$ & $\mathrm{ns}$ & $\mathrm{Q}$ & $\mathrm{ns}$ \\
$\mathrm{R}^{2}$ & 0,99 & - & 0,96 & - \\
CV (\%) & 2,63 & 3,54 & 2,92 & 11,91 \\
Probabilidade (\%) & 0,01 & 18,51 & 0,16 & 15,07 \\
\hline
\end{tabular}

$\mathrm{Q}=$ efeito quadrático do nível de GIM; $\mathrm{ns}=$ não significativo pelo teste $\mathrm{F}(\mathrm{P}>0,05) ; \mathrm{R}^{2}=$ coeficiente de determinação; $\mathrm{CV}=$ coeficiente de variação.

Valores seguidos por letras distintas na mesma coluna diferem entre si pelo teste Tukey $(\mathrm{P}<0,05)$.

$\mathrm{Na}$ equação, o ponto de curvatura máxima foi de $36,9 \%$ de substituição do milho por GIM, ou de $21,9 \%$ de inclusão do GIM na dieta, para o ganho de peso, e o ponto de curvatura mínima foi de $31,3 \%$ de substituição do milho por GIM, ou de $18,5 \%$ de inclusão do GIM na dieta, para o índice de conversão alimentar. 
Para o período de 22 a 38 dias (Tab. 5), houve efeito quadrático para: ganho de peso $(\mathrm{Y}=$ $\left.1278,78+0,3112 X-0,00429 X^{2}\right)$, consumo de ração $\left(Y=2241,47+6,442 X-0,0569 X^{2}\right)$ e índice de conversão alimentar $(\mathrm{Y}=1,753+$ $\left.0,00465 X-0,0000389 X^{2}\right)$, mas não para o índice de mortalidade.

Tabela 5. Ganho de peso (GP), consumo de ração $(\mathrm{CR})$, índice de conversão alimentar (CA) e índice de mortalidade (Mort) de frangos de corte alimentados com dietas contendo níveis crescentes de substituição do milho por gérmen integral de milho (GIM) na fase de crescimento (22 a 38 dias de idade)

\begin{tabular}{|c|c|c|c|c|}
\hline $\begin{array}{l}\text { Nível de } \\
\text { substituição (\%) }\end{array}$ & GP (g) & CR (g) & $\mathrm{CA}(\mathrm{g} / \mathrm{g})$ & Mort (\%) \\
\hline 0 & $1276,4 \mathrm{ab}$ & $2258,5 b$ & $1,769 \mathrm{c}$ & 1,3 \\
\hline 33 & $1291,4 \mathrm{a}$ & $2342,0 \mathrm{ab}$ & $1,816 \mathrm{~b}$ & 0,0 \\
\hline 67 & $1273,3 \mathrm{ab}$ & $2467,4 \mathrm{a}$ & $1,938 \mathrm{a}$ & 0,7 \\
\hline 100 & $1269,3 b$ & $2299,1 b$ & $1,812 b$ & 1,3 \\
\hline Efeito & Q & Q & Q & ns \\
\hline $\mathrm{R}^{2}$ & 0,71 & 0,77 & 0,87 & - \\
\hline CV $(\%)$ & 2,79 & 2,89 & 2,86 & 13,49 \\
\hline Probabilidade (\%) & 0,06 & 0,52 & 0,06 & 18,02 \\
\hline
\end{tabular}

O ponto de curvatura máxima foi de $36,2 \%$, $56,5 \%$ e $59,6 \%$ de substituição do milho por GIM para o ganho de peso, consumo de ração e índice de conversão alimentar, respectivamente. Convertendo-se esses valores para o ponto de inclusão, têm-se os seguintes resultados: $22,5 \%$, $35,1 \%$ e $37,0 \%$ de inclusão do GIM na dieta para o ganho de peso, consumo de ração e índice de conversão alimentar, respectivamente.

No período de 39 a 47 dias (Tab. 6), não foi observado nenhum efeito significativo para as variáveis analisadas.

Segundo Maiorka et al. (2002), o desenvolvimento da mucosa intestinal ocorre pela presença dos agentes tróficos, que melhoram o processo mitótico e, como conseqüência, aumentam o número de células e tamanho dos vilos. Para os autores, o alimento no lúmen intestinal é o principal agente trófico, em processo que se inicia logo após o alojamento das aves, mas ganha ritmo acelerado após o quinto dia de vida. Assim, diferente do observado no período de um a sete dias, era esperada maturidade suficiente do trato digestivo das aves para que ocorresse melhor digestão do GIM, mesmo com os níveis de gordura e fibra altos na dieta.

Tabela 6. Ganho de peso (GP), consumo de ração (CR), índice de conversão alimentar (CA) e índice de mortalidade (Mort) de frangos de corte alimentados com dietas contendo níveis crescentes de substituição do milho por gérmen integral de milho (GIM) na fase de final (39 a 47 dias de idade)

\begin{tabular}{|c|c|c|c|c|}
\hline $\begin{array}{l}\text { Nível de } \\
\text { substituição (\%) }\end{array}$ & GP (g) & CR (g) & CA (g/g) & Mort (\%) \\
\hline 0 & 650,6 & 1568,4 & 2,431 & 1,3 \\
\hline 33 & 654,7 & 1565,3 & 2,391 & 0,0 \\
\hline 67 & 632,1 & 1621,8 & 2,580 & 1,8 \\
\hline 100 & 600,6 & 1627,4 & 2,715 & 1,8 \\
\hline Efeito & ns & ns & $\mathrm{ns}$ & ns \\
\hline CV (\%) & 4,44 & 4,25 & 6,56 & 14,85 \\
\hline Probabilidade (\%) & & & 25,71 & 13,52 \\
\hline
\end{tabular}

Os piores resultados de desempenho foram obtidos com $100 \%$ de substituição do milho por GIM, em que o provável motivo é o aumento dos níveis de EE e FB, como observado na Tab. 2. Para Larbier e Leclerq (1994), os níveis de FB afetam a digestibilidade das rações para aves por dois motivos principais: aumento na taxa de passagem da ingesta pelo TGI, o que diminui o tempo de permanência e, como conseqüência, o tempo de ação das enzimas digestivas, e a atuação da fibra como barreira à ação das enzimas digestivas, principalmente no duodeno.

Resultados positivos foram observados quando se avaliou o nível intermediário de substituição, principalmente para o ganho de peso, em que se recomendam $21,9 \%$ e $22,5 \%$ de inclusão do GIM na dieta no período de oito a 21 dias e de 22 a 38 dias, respectivamente. Esses resultados indicam não-restrição ao uso do GIM na fase final.

É possível realizar comparação entre os resultados obtidos com o GIM, para o desempenho, com alguns trabalhos de frangos de corte alimentados com milho alto óleo na dieta, dado que o aumento do conteúdo de óleo é obtido pelo aumento da fração do gérmen no grão. 
Lima (2001), ao avaliar a utilização de duas dietas isoenergéticas, a primeira com milho alto óleo como ingrediente energético e a segunda, com milho comum mais óleo de soja sobre o desempenho de frangos de corte, observou melhores valores para ganho de peso e redução do consumo de ração. $\mathrm{O}$ aumento no ganho de peso, segundo o autor, pode ser explicado pela diferença dos valores energéticos do óleo do milho em comparação com o da soja. Rostagno et al. (2000) atribuíram ao óleo de soja o valor de EMAn de $8.790 \mathrm{kcal} / \mathrm{kg}$, enquanto o mesmo índice para o óleo de milho foi de $8.886 \mathrm{kcal} / \mathrm{kg}$.

Outro aspecto observado foi o pior índice de conversão alimentar com a adição do GIM na dieta, principalmente na fase de crescimento, em decorrência da diminuição da densidade da dieta, gerando maior desperdício da ave ao consumo. Chegou-se a esta conclusão mediante comparação realizada entre a densidade do milho grão, milho moído e do GIM, em que foi possível observar que o GIM foi cerca de 33,4\% menos denso do que o milho grão.

Os resultados de peso vivo (PV), de peso de carcaça $(\mathrm{PC})$ e de rendimento de carcaça $(\mathrm{RC})$ (Tab. 7) indicam efeito linear negativo para o rendimento de carcaça $(\mathrm{Y}=80,268-0,0197 \mathrm{X})$, mas não para peso vivo e para peso de carcaça.
Tabela 7. Peso vivo (PV), peso de carcaça (PC) e rendimento de carcaça (RC) para frangos de corte alimentados com diferentes níveis de gérmen integral de milho (GIM) em substituição ao milho em dietas no período de oito a 47 dias

\begin{tabular}{lccc}
$\begin{array}{l}\text { Nível de } \\
\text { substituição (\%) }\end{array}$ & PV $(\mathrm{g})$ & PC $(\mathrm{g})$ & RC (\%) \\
\hline 0 & 2734,4 & 2191,6 & $80,2 \mathrm{a}$ \\
33 & 2703,1 & 2149,1 & $79,5 \mathrm{ab}$ \\
67 & 2728,1 & 2169,7 & $79,5 \mathrm{ab}$ \\
100 & 2634,4 & 2053,8 & $78,0 \mathrm{~b}$ \\
Efeito & $\mathrm{ns}$ & $\mathrm{ns}$ & $\mathrm{L}$ \\
$\mathrm{R}^{2}$ & - & - & 0,83 \\
CV (\%) & 4,59 & 4,99 & 1,19 \\
Probabilidade (\%) & 15,73 & 5,61 & 0,37 \\
\hline
\end{tabular}

$\mathrm{L}=$ efeito linear do nível de GIM; ns = não significativo pelo teste $\mathrm{F}(\mathrm{P}>0,05) ; \mathrm{R}^{2}=$ coeficiente de determinação; $\mathrm{CV}=$ coeficiente de variação.

Valores seguidos por letras distintas na mesma coluna diferem entre si pelo teste Tukey $(\mathrm{P}<0,05)$.

Os dados referentes ao rendimento de cortes em relação ao peso vivo e ao peso de carcaça, apresentados nas Tab. 8 e 9, respectivamente, indicam efeito linear negativo para percentagem de gordura, quando comparado ao peso vivo $(\mathrm{Y}=$ $1,660-0,00691 \mathrm{X})$ e peso de carcaça $(\mathrm{Y}=2,0747$ $-0,008334 \mathrm{X})$, e efeito linear positivo para peso de pés, pescoço e cabeça $(\mathrm{Y}=13,174+$ 0,00819X), quando comparado ao peso da carcaça.

Tabela 8. Rendimento de peito (PP), de coxa e sobrecoxa (PCx), de dorso (PD), de asa (PA), de pé, pescoço e cabeça (PPc) e de gordura abdominal (Gord) em relação ao peso vivo para frangos de corte alimentados com diferentes níveis de gérmen integral de milho (GIM) em substituição ao milho em dietas no período de oito a 47 dias

\begin{tabular}{lcccccc}
\hline $\begin{array}{l}\text { Nível de } \\
\text { substituição (\%) }\end{array}$ & PP (\%) & PCx (\%) & PD (\%) & PA (\%) & PPc (\%) & Gord (\%) \\
\hline 0 & 23,1 & 25,2 & 11,9 & 7,9 & 10,5 & $1,7 \mathrm{a}$ \\
33 & 23,2 & 24,7 & 11,4 & 8,0 & 10,8 & $1,4 \mathrm{~b}$ \\
67 & 23,5 & 24,3 & 11,6 & 8,0 & 10,8 & $1,2 \mathrm{bc}$ \\
100 & 22,1 & 24,2 & 11,6 & 8,9 & 11,0 & $1,0 \mathrm{c}$ \\
Efeito & $\mathrm{ns}$ & $\mathrm{ns}$ & $\mathrm{ns}$ & $\mathrm{ns}$ & $\mathrm{ns}$ & $\mathrm{L}$ \\
$\mathrm{R}^{2}$ & - & - & - & - & - & 0,99 \\
CV (\%) & 3,79 & 2,23 & 3,82 & 11,65 & 2,37 & 18,33 \\
Probabilidade (\%) & 10,45 & 6,34 & 21,60 & 7,56 & 5,79 & 0,02 \\
\hline
\end{tabular}

$\mathrm{L}=$ efeito linear do nível de GIM; ns= não significativo pelo teste $\mathrm{F}(\mathrm{P}>0,05) ; \mathrm{R}^{2}=$ coeficiente de determinação; $\mathrm{CV}=$ coeficiente de variação.

Valores seguidos por letras distintas na mesma coluna diferem entre si pelo teste Tukey $(\mathrm{P}<0,05)$. 
Tabela 9. Rendimento de peito (PP), de coxa e sobrecoxa (PCx), de dorso (PD), de asa (PA), de pé, pescoço e cabeça (PPc) e de gordura abdominal (Gord) em relação ao peso da carcaça eviscerada para frangos de corte alimentados com diferentes níveis de gérmen integral de milho (GIM) em substituição ao milho em dietas no período de oito a 47 dias

\begin{tabular}{lcccccc}
\hline $\begin{array}{l}\text { Nível de } \\
\text { substituição (\%) }\end{array}$ & PP (\%) & PCx (\%) & PD (\%) & PA (\%) & PPc (\%) & Gord (\%) \\
\hline 0 & 28,9 & 31,5 & 14,9 & 9,9 & $13,1 \mathrm{~b}$ & $2,1 \mathrm{a}$ \\
33 & 29,2 & 31,4 & 14,4 & 10,0 & $13,6 \mathrm{a}$ b & $1,8 \mathrm{~b}$ \\
67 & 29,6 & 30,6 & 14,6 & 10,1 & $13,6 \mathrm{ab}$ & $1,5 \mathrm{bc}$ \\
100 & 28,4 & 31,1 & 14,9 & 11,5 & $14,1 \mathrm{a}$ & $1,3 \mathrm{c}$ \\
Efeito & $\mathrm{ns}$ & $\mathrm{ns}$ & $\mathrm{ns}$ & $\mathrm{ns}$ & $\mathrm{L}$ & $\mathrm{L}$ \\
$\mathrm{R}^{2}$ & - & - & - & - & 0,89 & 0,99 \\
CV (\%) & 3,20 & 1,68 & 3,89 & 12,10 & 2,21 & 18,59 \\
Probabilidade (\%) & 31,14 & 6,25 & 43,02 & 5,85 & 5,00 & 0,03 \\
\hline
\end{tabular}

$\mathrm{L}=$ efeito linear do nível de GIM; ns= não significativo pelo teste $\mathrm{F}(\mathrm{P}>0,05) ; \mathrm{R}^{2}=$ coeficiente de determinação; $\mathrm{CV}=$ coeficiente de variação.

Valores seguidos por letras distintas na mesma coluna diferem entre si pelo teste Tukey $(\mathrm{P}<0,05)$.

De acordo com Turke (1982), dietas com alta FB diminuem a deposição de aminoácidos na massa muscular, o que pode explicar a redução linear do rendimento de carcaça com a adição do GIM na dieta. Isto não ocorreu para o peso relativo de cortes, pois não foi observada diferença $(\mathrm{P}>0,05)$ entre os tratamentos, exceto para peso de pés, pescoço e cabeça em relação ao peso da carcaça (Tab. 9).

Moreira et al. (2002), em análise dos efeitos da gordura sobre a qualidade de cortes em frangos de corte, concluíram que o aumento da EM (2.950 para 3.00 na fase inicial, 3.050 para 3.200 na fase de crescimento e 3.150 para 3.300 na fase final) não foi determinante para que se observassem diferenças significativas no peso do filé e na qualidade da carne de peito em frangos de corte. Os autores atribuíram esse fato à baixa relação entre a densidade energética da dieta e a deposição de aminoácidos musculares.

\section{CONCLUSÕES}

O gérmen integral de milho (GIM) não é um ingrediente ideal para a melhorar os valores de desempenho na fase pré-inicial para frangos de corte, mas se mostrou eficaz para as outras fases de criação nos níveis de inclusão de 21,9\%, $22,5 \%$ de GIM nos períodos de oito a 21 dias e 22 a 38 dias, respectivamente. Quanto ao GIM, na fase final (39 a 47 dias de idade) não há restrição ao seu uso. O rendimento de carcaça não foi afetado pela substituição do milho pelo
GIM, mas houve redução da percentagem de gordura abdominal.

\section{REFERÊNCIAS BIBLIOGRÁFICAS}

ADAMS, M.H.; WATKINS, A.L.; WALDROUP, P.W. et al. Factors affecting the metabolizable energy content poultry feedstuffs. J. Appl. Poult. Res., v.3, p.146-156, 1994.

BENITEZ, J.A.; GERNATA.G.; MURILLO, J.G. et al. The use of high oil corn in broiler diets. Poult. Sci., v.78, p.861-865, 1999.

BRITO, A.B. Avaliação nutricional do gérmen integral de milho para as aves e no desempenho de frangos de corte. 2002. 72f. Dissertação (Mestrado) - Escola de Veterinária, Universidade Federal de Goiás, Goiânia, GO.

BUTOLO, E.A.F.; NOBRE, P.T.C.; BOTELHO, F.G. A. et al. Determinação do valor nutricional energético e nutritivo do gérmen de milho desengordurado para frangos de corte. In: CONFERÊNCIA APINCO DE CIÊNCIA E TECNOLOGIA AVÍCOLAS, 1998, Campinas. Anais... Campinas: FACTA, 1998. p.40.

COMPÊNDIO brasileiro de alimentação animal. São Paulo:SINDI-RAÇÕES, 1985. 198p.

FURLAN, R.L.; MACARI, M. Lipídios: digestão e absorção. In: MACARI, M.; FURLAN, R.L.; GONZALES, E. Fisiologia aviária aplicada a frangos de corte. Jaboticabal:FUNEP/UNESP, 2002. p.143-148. 
GARCIA, E.R.M.; MURAKAMI,A.E.; BRANCO, A.F. et al. Efeito da suplementação enzimática em rações com farelo de soja e soja integral extrusada sobre a digestibilidade de nutrientes, o fluxo de nutrientes na digesta ileal e o desempenho de frangos. Rev. Bras. Zootec., v.29, p.1414-1426, 2000.

LARBIER, M.; LECLERQ, B. Nutrition and feeding of poultry. Nothingham: Nottingham University, 1994. 350p.

LIMA, G.J.M.M. Grãos de alto valor nutricional para a produção de aves e suínos: oportunidades e perspectivas. In: REUNIÃO ANUAL DA SOCIEDADE BRASILEIRA DE ZOOTECNIA, 38., 2001, Piracicaba. Anais... Piracicaba: FEALQ, 2001.p.178-194.

MAIORKA, A.; BOLELI, I.C.; MACARI, M. Desenvolvimento e reparo da mucosa intestinal. In: MACARI, M.; FURLAN, R.L.; GONZALES, E. Fisiologia aviária aplicada a frangos de corte. Jaboticabal: FUNEP/UNESP, 2002. p.143-148.

MOREIRA, J.; MENDES, A.A.; ROÇA, R.O. et al. Efeito da densidade, linhagem, sexo e nível de energia da dieta sobre o rendimento e qualidade da carne de peito em frangos de corte. Rev. Bras. Ciên. Avic., supl. 4, p.3, 2002.

PARSONS, C.M.; ZHANG, Y.; ARABA, M. Availability of aminoacids in high-oil corn. Poult. Sci., v.77, p.1016-1019, 1998.

PENZ Jr., A.M. Rações peletizadas para frangos de corte. In: SIMPÓSIO GOIANO DE AVICULTURA, 5., 2002, Goiânia. Anais... Goiânia: UFG, 2002. p.145-164.

PENZ Jr., A.M.; VIEIRA, S.L. Características nutricionais da dieta de primeira semana de pintos. In: SIMPÓSIO GOIANO DE AVICULTURA， 3., 1998, Goiânia. Anais... Goiânia: UFG, 1998. p.21-28.

REGINA, R.; SOLFERINI, O. Produção de cultivares de ingredientes de alto valor nutricional: características e benefícios. In: SIMPÓSIO SOBRE INGREDIENTES NA ALIMENTAÇÃO ANIMAL, 2., 2002, Uberlândia. Anais... Campinas: CBNA, 2002. p.105-116.

ROSTAGNO, H.S.; ALBINO, L.F.T.; DONZELE, J.L. et al. Tabelas brasileiras para aves e suínos: composição de alimentos $e$ exigências nutricionais. Viçosa: UFV - Imprensa Universitária, 2000. 61p.

SCOTT, T.A.; BOLDAJI, F. Comparison of inert markers [Chromic oxide or insoluble ash (CeliteTM)] for determining apparent metabolizable energy of wheat or barley-based broilers diets with or without enzymes. Poult. Sci., v.76, p.594-598, 1997.

SERAFIN, J.A.; NESHEIM, M.C. Influence of dietary heat-labile factors in soybean meal upon bile acid pool and turnover in the chick. J. Nutr., v.80, p.786-796, 1970.

SISTEMA de análises estatísticas e genéticas. Versão 7.1. SAEG: Viçosa, UFV, 1997. 150p.

TEICHMANN, H.F.; LÓPEZ, J.; LÓPEZ, S.E. Efeito da fitase na biodisponibilidade do fósforo em dietas com farelo de arroz integral para frangos de corte. Rev. Bras. Zootec., v.27, p.338344, 1998.

TURKE, D.E. The anatomy oh the avian digestive tract as related to feed utilization. Poult. Sci., v.61, p.1225-1224, 1982. 